\title{
Characterization of tellurium layers for back contact formation on close to technology treated CdTe surfaces
}

Cite as: Journal of Applied Physics 94, 3589 (2003); https://doi.org/10.1063/1.1597757

Submitted: 22 April 2003 • Accepted: 12 June 2003 • Published Online: 19 August 2003

D. Kraft, A. Thissen, J. Broetz, et al.

\section{ARTICLES YOU MAY BE INTERESTED IN}

Effects of the Au/CdTe back contact on IV and CV characteristics of Au/CdTe/CdS/TCO solar cells

Journal of Applied Physics 81, 2881 (1997); https://doi.org/10.1063/1.363946

A photoemission determination of the band diagram of the Te/CdTe interface

Journal of Applied Physics 77, 4489 (1995); https://doi.org/10.1063/1.359444

Effect of nitric-phosphoric acid etches on material properties and back-contact formation of ColTe-based solar cells

Journal of Vacuum Science \& Technology A 17, 805 (1999); https://doi.org/10.1116/1.581651

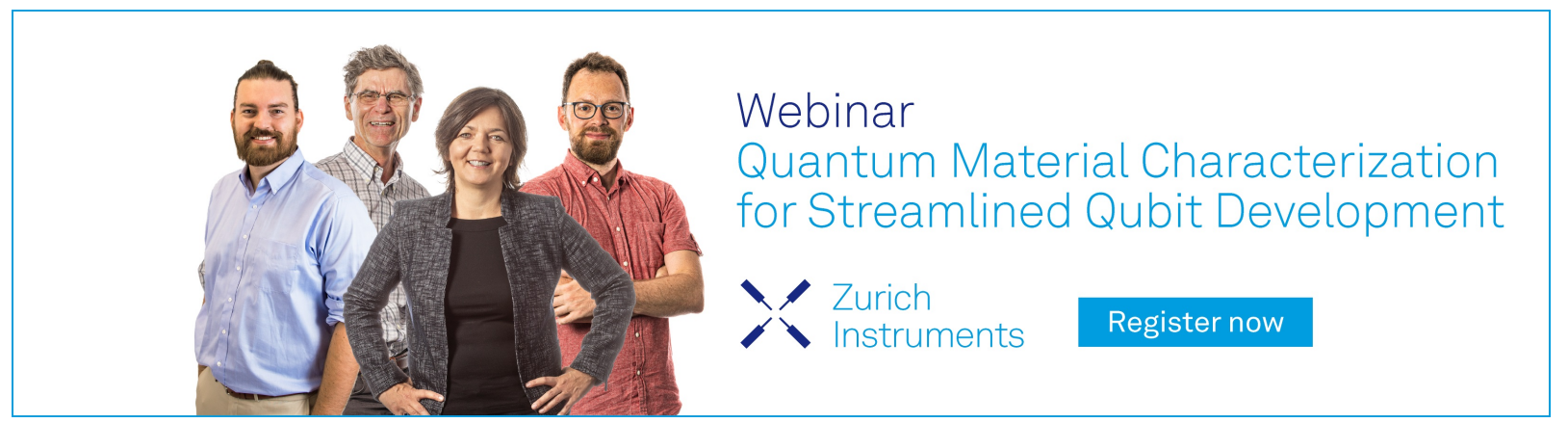




\title{
Characterization of tellurium layers for back contact formation on close to technology treated CdTe surfaces
}

\author{
D. Kraft, A. Thissen, ${ }^{\text {a) }}$ J. Broetz, and S. Flege \\ Darmstadt University of Technology, Institute of Materials Science, Petersenstrasse 23, \\ D-64287 Darmstadt, Germany \\ M. Campo \\ ANTEC Technology GmbH, Dr. Bonnet Weg 1, D-99310 Arnstadt, Germany
}

A. Klein and W. Jaegermann

Darmstadt University of Technology, Institute of Materials Science, Petersenstrasse 23, D-64287 Darmstadt, Germany

(Received 22 April 2003; accepted 12 June 2003)

\begin{abstract}
We have studied the contact formation on CdTe surfaces following the technologically applied procedure. The electronic properties of wet chemically etched CdTe surfaces has been investigated with photoelectron spectroscopy. For the characterization of the morphology, structure, and elemental distribution in the etched layer atomic force microscopy, scanning electron microscopy, grazing incidence x-ray diffraction, and secondary ion mass spectroscopy have been used. Etching of the samples has been performed in air and in an electrochemistry chamber directly attached to the UHV system. In both cases the formation of an elemental polycrystalline Te layer with a thickness of about $80 \AA$ is detected. For comparison, a thin Te layer has been deposited by physical vapor deposition onto a CdTe substrate. We determine a valence-band offset of $\Delta E_{\mathrm{VB}}=0.5 \pm 0.1 \mathrm{eV}$, independent of the preparation of the interface. (C) 2003 American Institute of Physics.
\end{abstract}

[DOI: $10.1063 / 1.1597757$ ]

\section{INTRODUCTION}

Thin-film solar cells based on CdTe absorber layers are on the threshold of commercialization with an expected high potential for cost reduction. Due to intensive research and development laboratory scale solar cells with high conversion efficiencies of about $16 \%^{1-4}$ have been realized in recent years. For widespread terrestrial applications, stable large area modules with efficiencies in the range of more than $10 \%$ are envisaged from the production lines. ${ }^{5}$ To complement and prove technological optimization, fundamental research is still needed to reach this aim.

The commonly used CdTe cell structure is composed of a float-glass substrate with the transparent front contact, usually a conducting indium tin oxide (ITO) layer covered with a thin $\mathrm{SnO}_{2}$ layer and the converting heterocontact $\mathrm{CdS} / \mathrm{CdTe} .^{1,5-9}$ After layer deposition, a subsequent $\mathrm{CdCl}_{2}-$ activation step is necessary to obtain good cell performance. ${ }^{6,710,11}$ Finally, the back contact is prepared.

For an understanding of the function and limitations of solar cells, a detailed knowledge of the electronic structure across the whole cell is essential. We have systematically investigated the different interfaces of CdTe thin-film solar cells with photoelectron spectroscopy in recent years. ${ }^{12-17}$ The conduction-band offsets at the $\mathrm{SnO}_{2} / \mathrm{CdS}$ (Refs. 12-14, and 18) and the CdS/CdTe (Refs. 14-16) interfaces have been found to be very small and are, therefore, expected to cause no limitations for cell efficiency. Nevertheless, the $\mathrm{SnO}_{2} / \mathrm{CdS}$ front contact cannot be considered as an ideal contact, because of the Fermi-level pinning at the $\mathrm{SnO}_{2}$

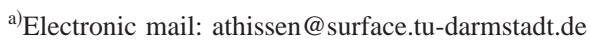

surface. ${ }^{12-14}$ The Fermi-level pinning leads to a Fermi-level position of $E_{\mathrm{CB}}-E_{F}=0.4-0.5 \mathrm{eV}$ at the $\mathrm{SnO}_{2}$ surface. As there is no conduction-band offset at the $\mathrm{SnO}_{2} / \mathrm{CdS}$ interface and the Fermi-level position is not altered with contact formation, ${ }^{12-14}$ there is a barrier for electron transport at this interface, which is also identified with electrical measurements. ${ }^{19}$

It is accepted that the back contact is one of the major limitations of CdTe solar cells. Current-voltage curves show the so-called roll-over phenomenon, which is attributed to a barrier for current transport at the back contact. ${ }^{19-21}$ From an analysis of electrical solar cell analysis, back contact barriers of the order of $0.5 \mathrm{eV}$ are expected. ${ }^{19-21}$ In addition to poor contact properties, it is accepted that degradation of cell performance depends on the type of back contact. ${ }^{22-24}$

Due to Fermi-level pinning at metal-semiconductor interfaces,${ }^{25}$ it is usually not possible to form ohmic contacts to semiconductors by just depositing metals onto them. Even in the (hypothetical) absence of Fermi-level pinning, an ohmic contact to the nominally $p$-doped CdTe is critical because of the large ionization potential of CdTe of $\sim 5.8 \mathrm{eV} .{ }^{13}$ Ohmic contacts to semiconductors are, therefore, generally formed by indiffusion of constituents of the contact material, which lead to high doping of the semiconductor. ${ }^{26,27}$ As a consequence of high doping, the space-charge layer associated with the barrier becomes very thin and can easily be tunneled by the charge carriers. Ohmic contacts are, therefore, typically not formed by low but by thin barriers.

Back contact materials studied for CdTe solar cells are $\mathrm{Au},{ }^{20,23} \mathrm{ZnTe},{ }^{28-30} \mathrm{Sb}_{2} \mathrm{Te}_{3},{ }^{24,31-35}$ and others. The best cells are achieved with $\mathrm{Cu}$-containing back contact materials, ${ }^{3,4,9}$ 
which are often combined with $\mathrm{Au}, \mathrm{ZnTe}$, and other materials. ${ }^{23,29,36}$ Although $\mathrm{Cu}$ itself does not lead to a small barrier for holes, the formation of a $\mathrm{Cu}_{2} \mathrm{Te}$ compound by chemical reaction of $\mathrm{Cu}$ with $\mathrm{CdTe}$ is assumed to provide a highly $p$-doped tunneling contact layer. ${ }^{37-39}$ Unfortunately, because of further diffusion of $\mathrm{Cu}$ into $\mathrm{CdTe}$ and the related formation of defects, solar cells made with such contacts are not stable. ${ }^{22,40}$

An alternative material is tellurium, which has a band gap of $0.33 \mathrm{eV}$. A tellurium layer on CdTe can be easily prepared by evaporation but also by chemical etching with nitric/phosphoric acid (NP etch). ${ }^{41}$ The latter procedure, combined with a subsequent metal layer deposition, is applied for stable CdTe solar cells and modules. ${ }^{5,9,23,24,31} \mathrm{Al}-$ though it has been concluded that a low barrier is obtained with evaporated $\mathrm{Te},{ }^{42,43}$ such contacts are not used in actual device preparation.

In this article, the influence of tellurium layers on the electronic properties of CdTe layers, which are deposited by close-spaced sublimation (CSS), is investigated with photoelectron spectroscopy and other techniques. Tellurium layers were formed by wet-chemical etching of the CdTe film with a mixture of nitric and phosphoric acid ("NP etch") as well as by thermal evaporation of Te. Etching has been performed either in air or in an electrochemistry chamber, which is directly attached to our integrated vacuum system. ${ }^{44}$ This in situ etching mostly eliminates contamination and the influence of oxygen. Initial results of our work have been presented earlier. ${ }^{13,14,17}$ This study follows the previous work by Niles and co-workers on the Te/CdTe interface prepared by wet-chemical etching and vacuum deposition. ${ }^{42,43}$ Our results, which are in part obtained using photoelectron spectroscopy induced by synchrotron light, provide a better insight of the role of tellurium for back contact formation in CdTe solar cells.

\section{EXPERIMENT}

The samples used in this study were taken from the CdTe thin-film solar cell production line of ANTEC GmbH. The conducting ITO layer and the $\mathrm{SnO}_{2}$ buffer layer were deposited onto a commercial glass substrate by a sputtering process. Afterward, the heterojunction layers $\mathrm{CdS}$ and $\mathrm{CdTe}$ were formed using $\mathrm{CSS}^{45}$ followed by a $\mathrm{CdCl}_{2}$ activation step. Finally, the samples were taken out of the production line. As a result, the topmost CdTe layer becomes oxidized. ${ }^{47}$

The further preparation has been carried out in the laboratory simulating the next step in the ANTEC production line: The wet-chemical treatment of the oxidized surface using an etching solution consisting of $1.3125 \mathrm{ml} \mathrm{HNO}_{3}$, $70 \mathrm{ml} \mathrm{H}_{3} \mathrm{PO}_{4}$, and $28 \mathrm{ml} \mathrm{H}_{2} \mathrm{O}$ distilled. The predicted chemical reactions are: ${ }^{41}$

$$
\begin{aligned}
3 \mathrm{CdTe}(s)+8 \mathrm{HNO}_{3}(\mathrm{aq}) \rightarrow & 3 \mathrm{Te}(s)+3 \mathrm{Cd}\left(\mathrm{NO}_{3}\right)_{2}(\mathrm{aq}) \\
& +2 \mathrm{NO}(g)+4 \mathrm{H}_{2} \mathrm{O}, \\
\mathrm{CdTe}(s)+4 \mathrm{HNO}_{3}(\mathrm{aq}) \rightarrow & \mathrm{Te}(s)+\mathrm{Cd}\left(\mathrm{NO}_{3}\right)_{2}(\mathrm{aq}) \\
+ & 2 \mathrm{NO}_{2}(g)+2 \mathrm{H}_{2} \mathrm{O} .
\end{aligned}
$$

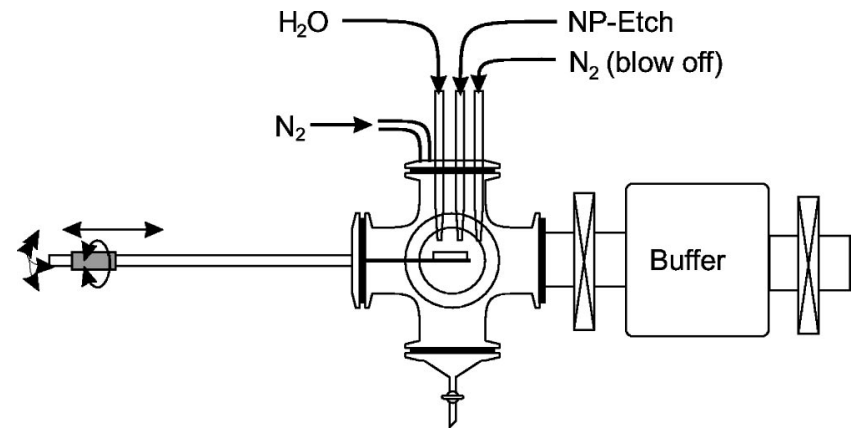

FIG. 1. Principle sketch of the electrochemistry chamber.

From Eqs. (1) and (2), it can be seen that an elemental Te layer is thought to form at the surface by preferential etching of $\mathrm{Cd}$. Therefore, oxidation of $\mathrm{Te}(2-\rightarrow 0)$ and dissolution of $\mathrm{Cd}^{2+}$ takes place. A detailed description of the etching procedure is given by Sarlund et al. ${ }^{41}$ To check the influence of the ambient conditions, the etching process has been carried out in two different manners:

(1) "Ex-situ:" dipping the sample into the PN etch, waiting for additional $10 \mathrm{~s}$ (total etching time about $1.5 \mathrm{~min}$ ) after the characteristic bubbles (gaseous etching byproducts) rise from the surface, rinsing with deionized water, drying with nitrogen gas and inserting it into the vacuum chamber (air exposure time approximately $10 \mathrm{~min}$ ).

(2) "In situ:" putting the sample into nitrogen atmosphere, forming a droplet of the PN-etch solution on the surface for $1 \mathrm{~min}$, rinsing with deionized water, drying with nitrogen gas, and inserting the sample directly into the vacuum without exposure to air.

For the "in situ"-etching, an electrochemistry chamber (Fig. 1) is used that allows sample manipulation and supplying etching solutions to the samples without contact to air in the left-hand side glass chamber and direct insertion into a vacuum by using a buffer chamber. ${ }^{44}$ For thermal evaporation of Te, a homemade effusion cell has been used. The Te deposition has been monitored with a quartz microbalance. For evaporation rates of about $3 \AA \mathrm{min}^{-1}$ a source temperature of $310^{\circ} \mathrm{C}$ has been used. During Te deposition, the CdTe substrate was kept at room temperature. For this investigation, the same oxidized CdTe samples as for the etching experiments have been used. To remove the surface oxide layer, the samples were sputtered using $\mathrm{Ar}^{+}$-ions with a kinetic energy of $1 \mathrm{keV}$ at $0.05 \mathrm{~mA} \mathrm{~cm}^{-2}$, an angle of incidence of $45^{\circ}$ and $4 \times 4 \mathrm{~mm}^{2}$ raster size before deposition. The removal of the surface oxide is achieved after approx. 10 minutes of sputtering, which corresponds to an oxide layer thickness of $\leqslant 1 \mathrm{~nm}$. As shown earlier etching under these conditions does not lead to changes in stoichiometry or to active defects. ${ }^{16}$

Photoelectron spectroscopy (PES) has been performed using a Phi 5700 multitechnique surface analysis system equipped with a monochromatized $\mathrm{Al}$ anode [X-ray photoelectron spectroscopy (XPS)], a He discharge lamp [ultraviolet photoelectron spectroscopy (UPS)], and a focusing sputter gun as well as an Omicron/VSW spectrometer system at the beamline U49/2 PGM2 at the synchrotron radiation 


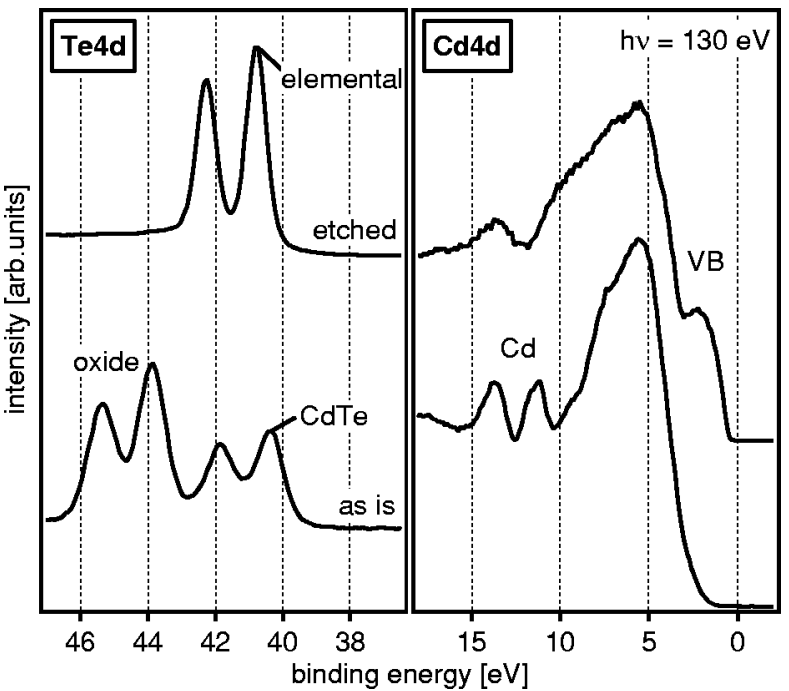

FIG. 2. SXP spectra taken at BESSY II of an untreated (as is) and an in situetched CdTe sample.

source BESSY II. The base pressure in both systems is $p$ $<10^{-9}$ mbar. To determine binding energies (BEs) and the different chemical components from the spectra the corelevel lines have been fitted using Voigt-shaped line profiles. BEs are given with respect to the Fermi level, which is calibrated using a sputter cleaned $\mathrm{Ag}$ sample ( $\mathrm{BE}\left[\mathrm{Ag} 3 d_{5 / 2}\right]$ $=368.27 \mathrm{eV}$ ).

The Fermi-level position of oxidized CdTe surfaces is given by $E_{F}-E_{\mathrm{VBM}}=1.0 \pm 0.1 \mathrm{eV}$, independent of $\mathrm{CdTe}$ substrate material. After removal of the oxide layer by sputtering, it is shifted to $E_{F}-E_{\mathrm{VBM}}=0.55 \pm 0.05 \mathrm{eV}$. This direct measurement of the surface Fermi-level position indicates that sputtering does not directly lead to a $n$-type CdTe surface, as has been deduced using electrical diode characteristics of CdTe/In Schottky barriers. ${ }^{46,47}$ After argon-ion sputtering of oxidized Sb-doped $p$-CdTe ingots, we observe a surface Fermi-level position $E_{F}-E_{\mathrm{VBM}}=0.4 \pm 0.1 \mathrm{eV},{ }^{48}$ which also indicates that sputtering itself does not lead to a $n$-type CdTe surface, at least under ultrahigh vacuum conditions.

Surface morphologies were observed by scanning electron microscopy (SEM) (Zeiss 962) and atomic force microscopy (AFM) (Thermomicroscopes CP). Structural examinations were performed using grazing incidence $\mathrm{x}$-ray diffraction (GIXRD) (Rigaku). For depth profile studies of the etched and deposited Te films with XPS, the same sputtering parameters as for surface cleaning have been chosen. Additional measurements were performed with secondary ion mass spectrometry (SIMS) (Cameca IMS 5F) using $\mathrm{Ar}^{+}$ ions either with an acceleration energy of $12.5 \mathrm{keV}$, ion beam currents of about $80 \mathrm{nA}$, and $500 \mu \mathrm{m}$ raster spot size.

\section{STRUCTURE OF ETCHED CLOSED-SPACE SUBLIMATION-CDTE FILMS}

\section{A. Composition and morphology}

Figure 2 shows soft $\mathrm{x}$-ray photoelectron (SXP) spectra for an untreated and therefore oxidized "as is" and an "in situ" etched sample. Before etching the Te $4 d$ signal shows a

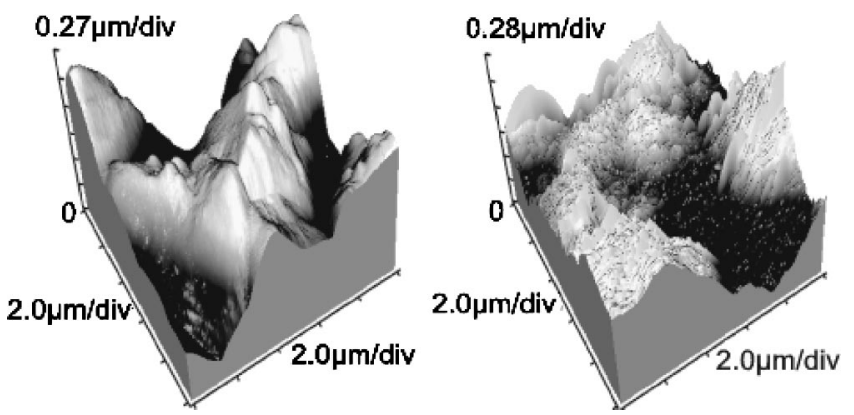

FIG. 3. Comparison of the AFM images of an as is (left-hand side) and $e x$ situ-etched CdTe sample (right-hand side).

strong oxidic component and a significantly weaker component from the CdTe substrate. The $\mathrm{Cd} 4 d$ emission is visible in the valence-band region. For the etched sample, no oxidic component is detectable. The shift toward higher BEs for the $\mathrm{Te} 4 d$ signal indicates a change in the oxidation state of the Te ions and, hence, the existence of an elemental Te layer at the surface, in agreement with literature..$^{24,41,42,49}$ The $\mathrm{Cd} 4 d$ signal has mainly disappeared from the spectrum so that a $\mathrm{Cd}$ depletion at the surface is obvious. The $\mathrm{Cd}$ concentration will be treated in more detail in Sec. III C. After etching, the $\mathrm{BE}$ of the valence-band maximum is about $1 \mathrm{eV}$ smaller than before. Therefore, a valence-band offset from CdTe to Te is evident. The surface morphology is affected by the etching process, which has also been observed by other groups. ${ }^{23,24}$ In Fig. 3, contact-mode AFM topography images of an untreated (left-hand side) and an etched CdTe sample (righthand side) are shown. No significant change in the general roughness is visible. The grain size is approximately $2-5 \mu \mathrm{m}$ with a height variation of about $1 \mu \mathrm{m}$. But the etching process obviously leads to a roughening of the surface on smaller scale. SEM images (Fig. 4) were taken in the backscattered electron (BSE) mode in order to observe an elemental contrast. The strong contrast between the grains and the widened grain boundaries in the image of the NP-etched surface indicates that preferential etching occurs along the grain boundaries. ${ }^{23,49}$ Furthermore, the surface image of the untreated sample looks diffuse and unfocused. This has been attributed by Bätzner et $a l .^{23}$ to a charging effect. In contrast, the better SEM contrast of the NP-etched sample also shows the formation of a conductive Te layer on the surface and possibly along the grain boundaries into the bulk of the layers.

X-ray diffraction (XRD) measurements (Fig. 5) have been performed in the common $\theta / 2 \theta$-as well as in the grazing incidence geometry to obtain a higher surface sensitivity. The $\theta / 2 \theta$ pattern shows the cubic CdTe substrate and a second phase with low reflection intensities, which can be clearly identified as a hexagonal Te phase (see, e.g., the reflection at $2 \theta=27.5$ ). The larger intensity of the Te reflections and the decreasing substrate intensities by using grazing incidence geometry shows that NP etching leads to the formation of a crystalline Te film on top of the CdTe substrate. With the full width at half maximum of the Te reflections, a minimum crystallite size of about $130 \AA$ can be es- 


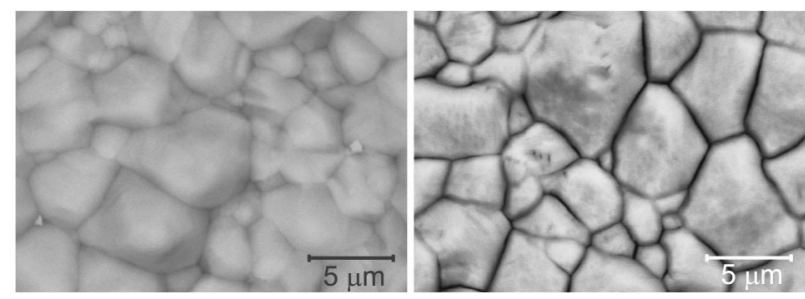

FIG. 4. SEM images (BSE mode) of an untreated (as is) and an ex situetched CdTe sample.

timated using Scherrer's equation. For the etched samples, $\mathrm{x}$-ray reflectometry cannot be used to determine the film thickness, because of the rather high surface roughness. Sarlund et $a l^{41}$ reported an amorphous Te layer immediately after extraction of CdTe from the etching solution and its crystallization after a time lapse of about $10 \mathrm{~min}$. In our case, the time elapsed between etching and the beginning of the XRD investigation amounts to $\sim 30 \mathrm{~min}$.

\section{B. SIMS depth profiling}

SIMS depth profiling has been performed to get additional information about the element distribution at the $\mathrm{CdTe} / \mathrm{Te}$ interface. In Fig. 6, the results are shown for differently treated samples. The depth profiles of the three samples are normalized due to the different ion beam currents. The untreated substrate [Fig. 6(a)] shows a depth independent $\mathrm{Te} / \mathrm{Cd}$ ratio. The depth profile of an ex situ etched sample [Fig. 6(b)] indicates a Te accumulation nearly by a factor of 2 and a $\mathrm{Cd}$ depletion at the surface compared to the bulk situation. The $\mathrm{Cd}$ intensity in the surface region is low but not zero. This result is also confirmed by the XPS investigation in Sec. III C also showing a nonvanishing surface $\mathrm{Cd}$ concentration after etching. Therefore, the existence of a gradually decreasing Cd concentration in the Te layer is evident. While for the Cd emission the bulk intensity is already reached after about $100 \mathrm{~s}$ of sputtering, the Te emission shows the intrinsic intensity after $200 \mathrm{~s}$. This indicates the formation of a thin crystalline Te layer on top of a Teenriched CdTe transition layer due to the etching process. A

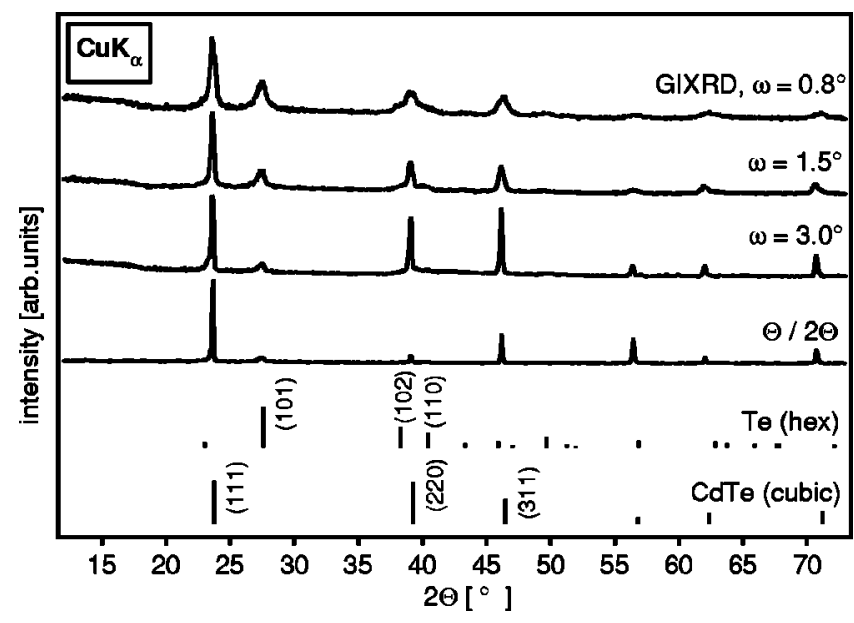

FIG. 5. XRD investigation of the ex situ-etched Te-layer with powder reflection positions (vertical lines) taken from the JCPDS database.

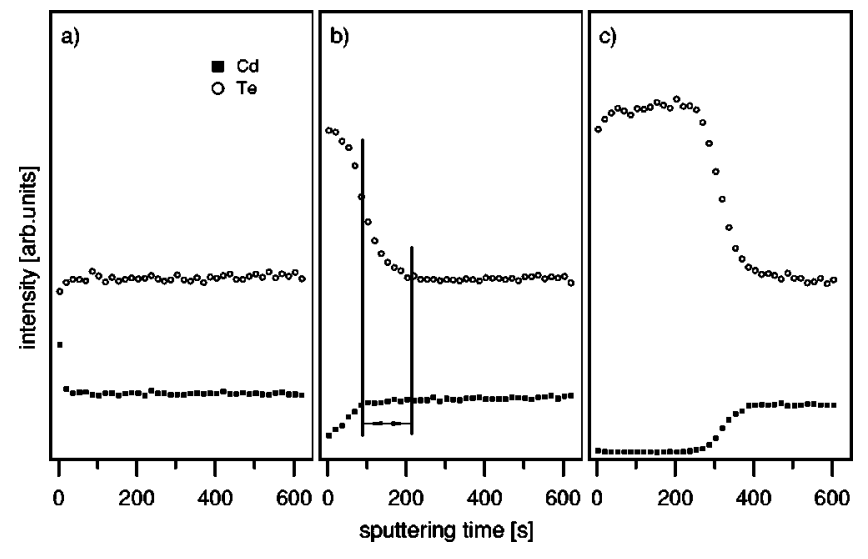

FIG. 6. SIMS examinations using $\mathrm{Ar}^{+}$ions for differently treated CdTe substrates: (a) Untreated, (b) chemical etched, and (c) Te covered by thermal evaporation.

reliable thickness determination of the Te accumulation layer is not possible, because of sputtering artifacts, like layer intermixing, the roughness of the polycrystalline CdTe substrates, and nonequilibrium starting conditions. Hence, a calibration sample has been prepared consisting of a $500 \AA$ thick physical vapor deposition (PVD) Te film on a sputter cleaned CdTe substrate. By comparing the depth profiles of the etched and PVD deposited samples, a Te film thickness of about $80 \AA$ for the etched sample may be calculated. However, the sputtering rates of the etched and PVD deposited samples may possibly deviate from each other due to different layer densities. In contrast to the etched sample, the Cd intensity in the PVD deposited Te film is zero. Therefore, the gradual change in $\mathrm{Cd}$ concentration observed for the etched sample is not a sputtering artifact.

\section{X-ray photoelectron spectroscopy depth profiling}

For an investigation of the interface properties at the $\mathrm{CdTe} / \mathrm{Te}$ interface, we have also applied XPS depth profiling. In general, depth profiling can lead to preferential sputtering. This will affect the observed composition but mainly the electronic properties of the surface. However, in the present case, this effect does not affect our measurements as Te is an elemental semiconductor. In addition, it has been shown that sputter depth profiling is well suited to determine electronic properties of CdTe interfaces. ${ }^{16}$ This is most likely explained by the similar atomic masses of $\mathrm{Cd}$ and $\mathrm{Te}$.

In Fig. 7, the results for an "ex situ"-etched CdTe film are shown. The surface of the untreated CdTe sample is oxidized. After etching, the intensity of the $\mathrm{Cd} 3 d$ emission is mostly reduced. The Te $3 d$ line is shifted to higher BEs due to the formation of elemental Te. There is still an oxidic Te component, indicating that the Te layer is partly oxidized. After $5 \mathrm{~min}$ of Ar sputtering, the oxides are completely removed. So the oxidation of the elemental Te layer is only a surface effect and there is no bulk Te oxide formed. With increasing sputtering time, the Te emissions seem to shift to lower BEs. This appearance is, however, not a shift of the surface Fermi-level position, but mostly the result of the gradual attenuation of elemental $\mathrm{Te}$ and the simultaneous increase of a second Te component at lower BEs. For interme- 


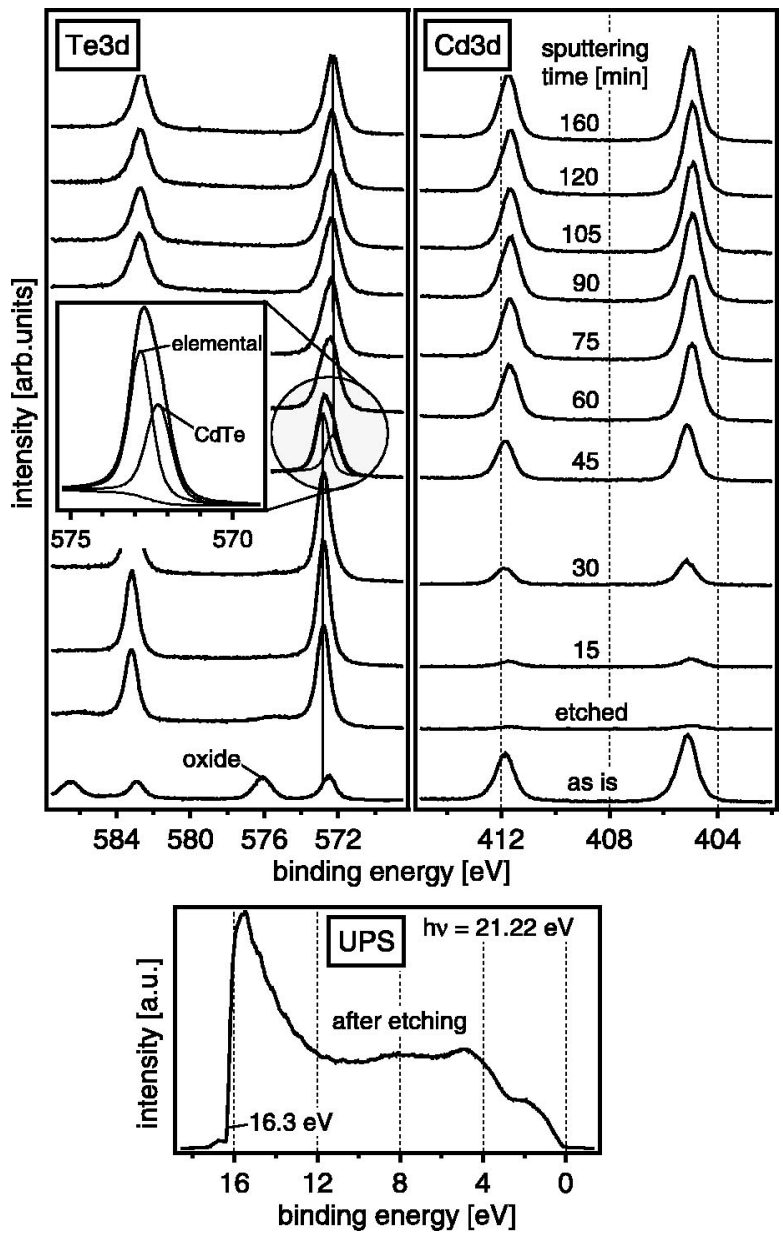

FIG. 7. X-ray photoelectron spectra $(h \nu=1486.6 \mathrm{eV})$ of an $e x$ situ-etched and subsequently Ar-sputtered CdTe sample (top) as well as an ultraviolet photoelectron spectra of the etched sample (bottom).

diate sputtering times, the Te peak is a superposition of these Te components. This is shown by the magnified peak for a sputtering time of $45 \mathrm{~min}$, which includes the decomposition of the Te $3 d_{5 / 2}$ peak, as performed by curve fitting (the BEs are given in Fig. 10).

In addition, the intensity of the $\mathrm{Cd} 3 d$ emission increases. Figure 8 shows the normalized $\mathrm{Te} 3 d$ and $\mathrm{Cd} 3 d$ intensities (maximum intensities of the lines correspond to unity) as derived from curve fitting of the spectra shown in Fig. 7. The intensities of the low BE Te $3 d$ component and of the $\mathrm{Cd} 3 d$ line show a parallel behavior. Furthermore, the BE difference between the low BE Te component and the $\mathrm{Cd} 3 d$ line is identical to the value for CdTe. The low BE Te component can, therefore, be attributed to emission from the CdTe bulk material.

\section{Discussion of the results}

Etching of CdTe leads to the formation of a Te layer on the surface. It occurs preferentially along the grain boundaries also in agreement with literature, ${ }^{23,42}$ as shown by our SEM and XPS depth profile data. The depth profiles show a very slow attenuation of the Te intensity, which is explained by the Te layer and covers the grains not only at the surface

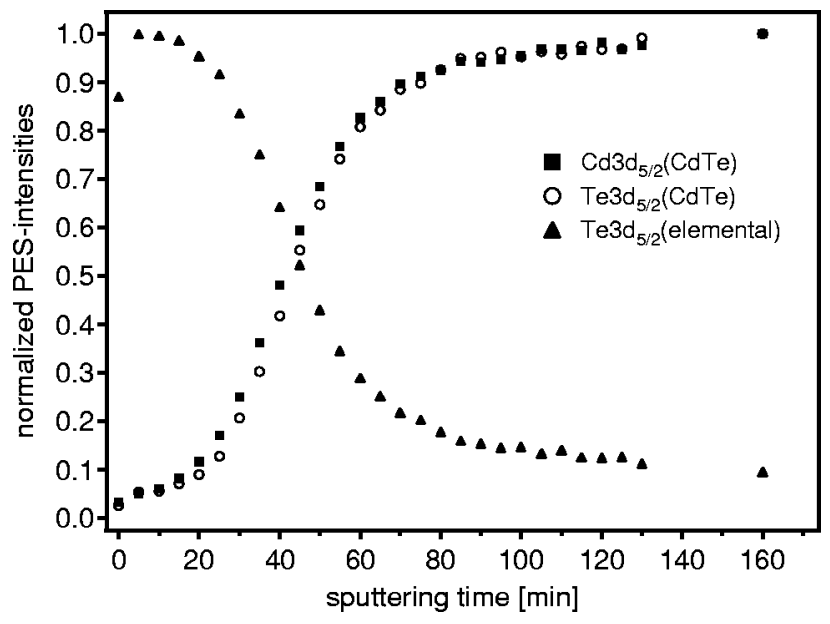

FIG. 8. Normalized photoelectron intensities as function of sputtering time of the ex situ experiment (see Fig. 7).

but also to some depth along the grain boundaries. The large scale morphology of etched polycrystalline CdTe layers is shown in Fig. 9(c).

Although it has been argued by Sarlund et al., ${ }^{41}$ that the solution also attacks the Te layer by formation and dissolution of $\mathrm{TeO}_{2},{ }^{41}$ the $\mathrm{Te}$ layer formed by chemical etching definitely needs to be porous, otherwise the solution would only be in contact with Te and not with CdTe. The porosity of the Te layer is indicated by white lines and inclusions in a magnified view of the Te layer, which is shown Fig. 9(a).

In addition to sputter depth profiles, which are performed using SIMS or Auger electron spectroscopy (see Sec. III B and Refs. 42 and 50), XPS depth profiles not only resolve the element concentrations but also the chemical composition of the etched surface. The etched surface of the polycrystalline CdTe films is evidently composed of a mixture of elemental $\mathrm{Te}$ and $\mathrm{CdTe}$. The remaining $\mathrm{Cd}$ emission has also been observed by Niles et al. ${ }^{42}$ at etched CdTe films. One possible explanation for this would be the formation of a graded transition region. Assuming a composition gradient $\mathrm{Cd}_{x} \mathrm{Te}_{1-x}$ with $x=0-0.5$ and the surface at $x=0$ as a result of etching, is not consistent with our measurements. A
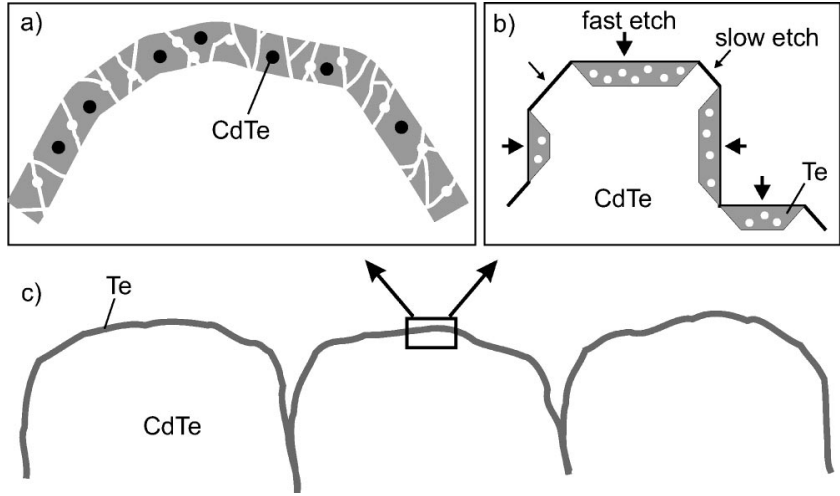

FIG. 9. Sketch of morphology of etched polycrystalline CdTe layers. A crystalline Te layer is formed on the surface and along the grains (c). The observation of CdTe with XPS after etching is either explained by CdTe inclusions in the Te layer (a) or by facet formation due to selective etching of different surface orientations (b). 


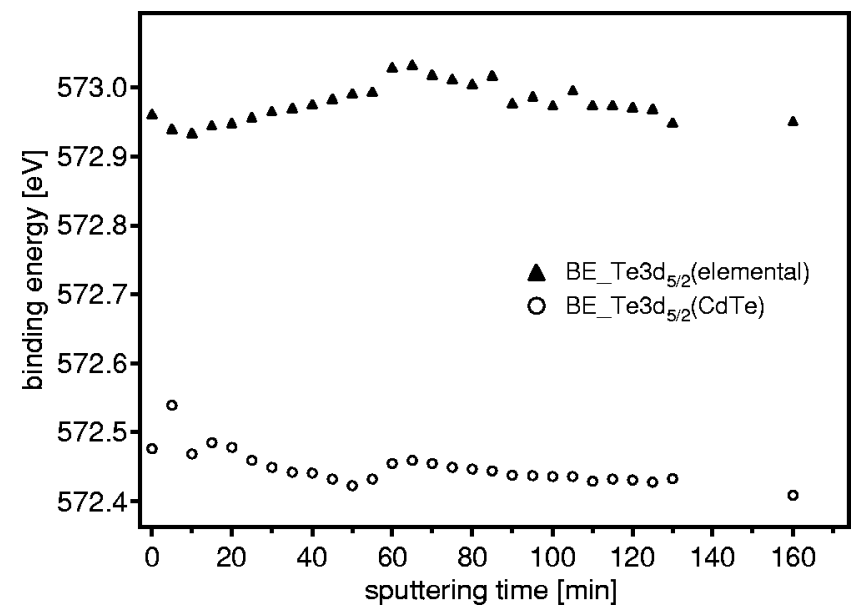

FIG. 10. BEs obtained from deconvolution of Te $3 d_{5 / 2}$ spectra taken during sputter depth profiling of an $e x$ situ-etched sample.

graded transition region is also not consistent with our XRD data, which gives clear evidence for the formation of a crystalline Te layer. Alternatively there might be CdTe inclusions inside a thicker Te layer. This explanation is more probable, since XRD suggests a Te layer thickness of $>130 \AA$ (see also, Ref. 41), which could not be penetrated by photoelectrons. An important observation in this context is that the etched surface always shows some remaining CdTe signal. This result is independent of the etching time, where we have used etching times of 5, 10, and 20 after the characteristic formation of bubbles. The structure of the surface is sketched in Fig. 9(a). An alternative model, which is also consistent with the presented data, is shown in Fig. 9(b). It is based on selective etching of different surface orientations, which is well known for compound semiconductors. ${ }^{51}$ The roughening of the surface with etching, as observed with AFM, is then explained by facet formation. The detection of CdTe with surface sensitive XPS, even after extensive etching, is explained within this model by areas where etching is slow, or even zero. Selective etching is consistent with the observation by Niles et al. ${ }^{42}$ which found a closed Te layer and no $\mathrm{Cd}$ on an etched single crystal $\mathrm{CdTe}(001)$ surface. However, additional measurements on different single crystal surface orientations are necessary to clarify the role of selective etching.

\section{ELECTRONIC PROPERTIES OF CDTE/TE INTERFACES}

\section{A. Chemically etched $\mathrm{CdTe} / \mathrm{Te}$ interface}

Important information on the function of the contact is obtained from the BEs of the spectra shown in Fig. 7. The BEs of the Te $3 d$ line as a function of sputtering time are shown in Fig. 10. The component with higher BEs corresponds to elemental Te, those at lower BEs to Te in CdTe as outlined herein. The BEs of the Te $3 d_{5 / 2}$ components are rather constant with $\mathrm{BE}(\mathrm{CdTe})=572.43 \pm 0.05 \mathrm{eV}$ and $\mathrm{BE}(\mathrm{Te})=572.96 \pm 0.05 \mathrm{eV}$. Although the $\mathrm{BE}$ difference seems to be somewhat smaller for low sputtering times, its overall variation is below $0.1 \mathrm{eV}$ with an average value of $\Delta \mathrm{BE}=0.51 \mathrm{eV}$. Photoelectron spectra have also been taken

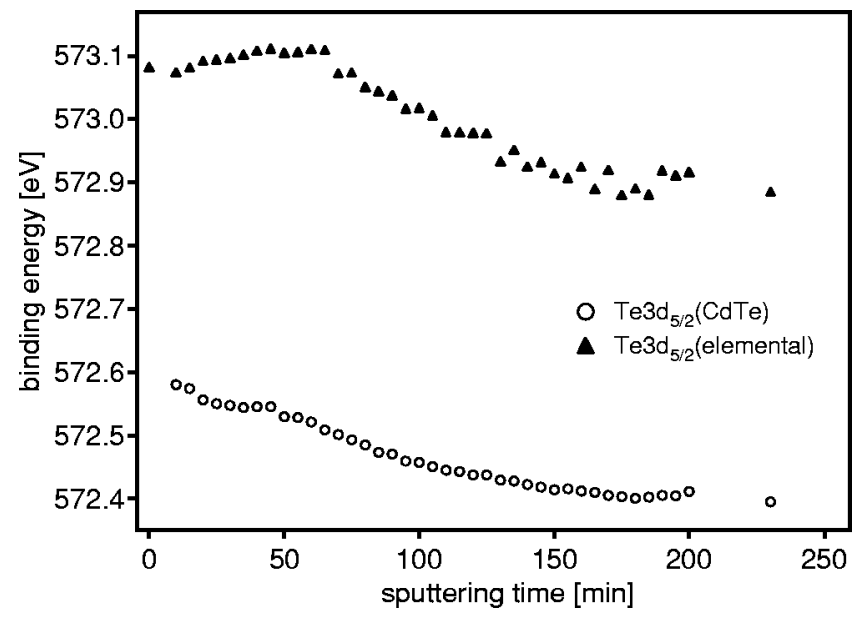

FIG. 11. BEs obtained from deconvolution of Te $3 d_{5 / 2}$ spectra taken during sputter depth profiling of an in situ-etched sample.

during sputter depth profiling of an in situ etched sample. The data are not shown here, since they are essentially identical to spectra presented in Fig. 7. One difference is the absence of an oxide component after etching. Therefore, a clean oxide-free $\mathrm{CdTe} / \mathrm{Te}$ interface can be prepared by this procedure. In Fig. 11, the BEs of the elemental Te and CdTe contributions to the $\mathrm{Te} 3 d_{5 / 2}$ line are shown as a function of the sputtering time. The tendency indicates some small differences from the results obtained from the ex situ experiment. Although the BE difference between the two components is also rather constant with $\Delta \mathrm{BE}=0.55 \pm 0.1 \mathrm{eV}$, the absolute values are different. For larger sputter times, however, the final $\mathrm{BEs}$ reached are $\mathrm{BE}(\mathrm{CdTe})=572.41$ $\pm 0.05 \mathrm{eV}$ and $\mathrm{BE}(\mathrm{Te})=572.92 \pm 0.05 \mathrm{eV}$, which is very close to the values obtained after sputter depth profiling of the $\mathrm{CdTe} / \mathrm{Te}$ interface prepared by ex situ etching.

The BEs from Figs. 10 and 11 can be transformed into corresponding energy band diagrams. First of all, the valence-band offset is determined from a core-level BE difference and the core-level BEs with respect to the valenceband maxima. ${ }^{52}$ Our experimental values are $\Delta \mathrm{BE}=0.51$ $\pm 0.05 \mathrm{eV} \quad$ and $\quad \mathrm{BE}_{\mathrm{Te} 3 d}(\mathrm{CdTe})-\mathrm{BE}_{\mathrm{VBM}}(\mathrm{CdTe})=571.75$ $\pm 0.05 \mathrm{eV}$ (see also Ref. 15). For the Te layers, we find $\mathrm{BE}_{\mathrm{Te} 3 d}(\mathrm{Te})-\mathrm{BE}_{\mathrm{VBM}}(\mathrm{Te})=572.78 \pm 0.04 \mathrm{eV}$, for seven different etched CdTe samples (ex situ as well as in situ) and $\mathrm{BE}_{\mathrm{Te} 3 d}(\mathrm{Te})-\mathrm{BE}_{\mathrm{VBM}}(\mathrm{Te})=572.74 \pm 0.03 \mathrm{eV}$ for four different evaporated Te layers. Using $572.76 \mathrm{eV}$ as an average value, the valence-band offset is calculated as $\Delta E_{\mathrm{VB}}=0.5$ $\pm 0.1 \mathrm{eV}$, with the valence band of Te above that of CdTe.

A complete energy band diagram further requires the positions of the Fermi level and the vacuum level, as well as of the conduction-band minima. The latter are derived by adding literature values for the band-gap $E_{g}(\mathrm{CdTe})$ $=1.49 \mathrm{eV}$ and $E_{g}(\mathrm{Te})=0.33 \mathrm{eV}$ (Ref. 53) to the valenceband position. We have derived the position of the vacuum level $E_{\text {vac }}$ using UPS measurements of thick CdTe and Te films, which determine the work function as well as the difference between the valence-band maximum and the Fermilevel $E_{F}-E_{\mathrm{VBM}}$. With these values, the ionization potential $I_{P}=E_{\mathrm{vac}}-E_{\mathrm{VB}}$ is determined, which is then added to the 


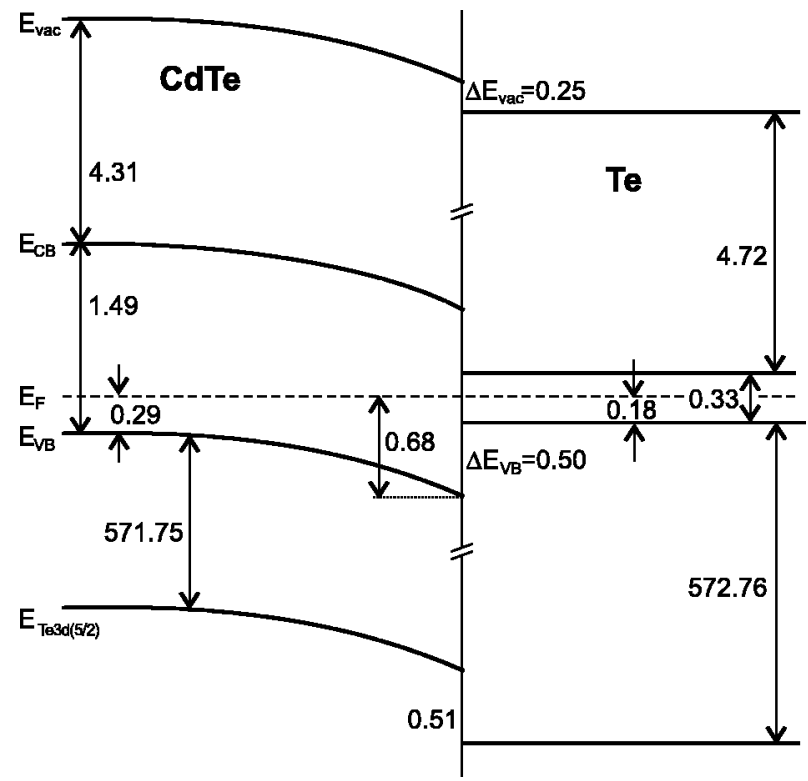

FIG. 12. Band energy diagram of the $\mathrm{CdTe} / \mathrm{Te}$ interface prepared by chemical etching of a CdTe substrate.

valence-band position. The ionization potentials are determined to be $I_{P}(\mathrm{CdTe})=5.8 \pm 0.1 \mathrm{eV}$ (see also Ref. 13) and $I_{P}(\mathrm{Te})=5.05 \pm 0.1 \mathrm{eV}$, respectively. The Fermi-level position at the interface is directly determined from the $\mathrm{BE}$ of $\mathrm{Te} 3 d_{5 / 2}(\mathrm{CdTe})(572.43 \pm 0.05 \mathrm{eV}$; Fig. 10) and its distance to the $\mathrm{CdTe}$ valence-band maximum $(571.75 \pm 0.1 \mathrm{eV})$, which results in $E_{F}=E_{\mathrm{VBM}}(\mathrm{CdTe})=0.68 \pm 0.1 \mathrm{eV}$ for the $e x$ situ experiment. For the in situ experiment, the BEs of the CdTe emissions are not constant, indicating a shift of the Fermi-level position during depth profiling. However, all CdTe BEs of the in situ experiment are larger, compared to those of the ex situ experiment. Hence, the Fermi-level position at the $\mathrm{CdTe} / \mathrm{Te}$ interface, which corresponds to the barrier for hole transport across the interface is $\geqslant 0.68 \mathrm{eV}$. We have determined the Fermi-level position of the sputter cleaned CdTe surface as $E_{F}-E_{\mathrm{VBM}}=0.65 \mathrm{eV}$ (see Sec. IV B). It is rather unlikely that this value also corresponds to the bulk Fermi-level position, as it would indicate an unreasonably low doping density. The hole density can be calculated using a valence-band density of states of $N_{V}=7.6$ $\times 10^{18} \mathrm{~cm}^{-3}$ (Ref. 53). Electrical measurements of CdTe solar cells indicate a doping density of $\sim 1 \times 10^{14} \mathrm{~cm}^{-3}$ (Ref. 54), which corresponds to $E_{F}-E_{\mathrm{VBM}}=0.29 \mathrm{eV}$. In Fig. 12, we have used this value for the bulk Fermi-level position.

\section{B. Vacuum evaporated $\mathrm{CdTe} / \mathrm{Te}$ interfaces}

Figure 13 shows $\mathrm{x}$-ray photoelectron spectra of a stepwise deposited Te layer onto a CdTe substrate. The untreated sample (as is) is oxidized before the prior sputtering step of $10 \mathrm{~min}$ (parameters discussed herein). This short sputtering time indicates that an air exposure of the samples for a long time only leads to a thin oxide layer at the surface. The smaller $\mathrm{BE}$ of the $\mathrm{Cd}$ and Te peaks after sputtering by about $0.3 \mathrm{eV}$ indicates a more $n$-doped surface of CdTe due to oxide formation. With increasing deposition time, a larger

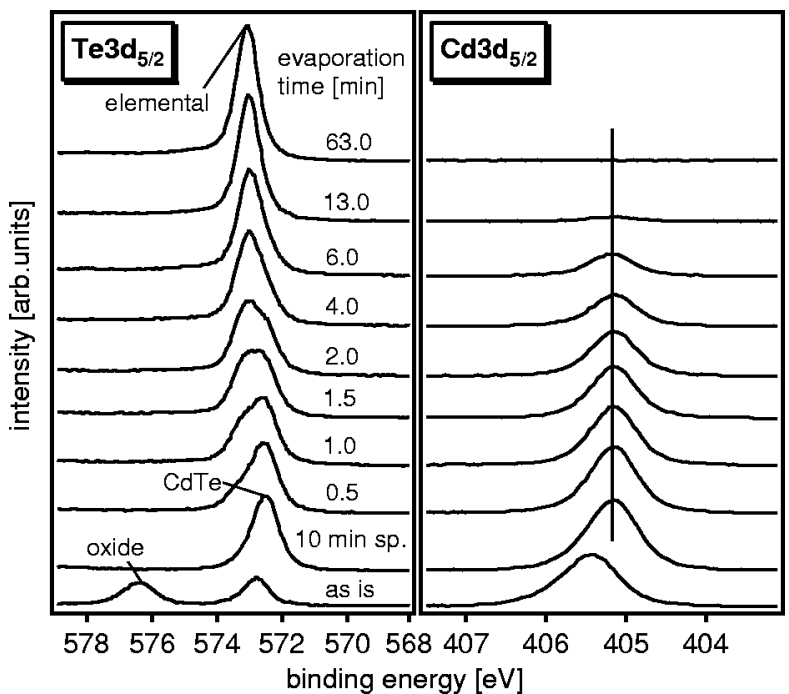

FIG. 13. X-ray photoelectron spectra of the $\mathrm{Te} 3 d_{5 / 2}$ and $\mathrm{Cd} 3 d_{5 / 2}$ core levels for a step-by-step Te deposition.

$\mathrm{BE}$ component in the Te $3 d_{5 / 2}$ emission appears, which is due to elemental Te. The $\mathrm{Te} 3 d(\mathrm{CdTe})$ and $\mathrm{Cd} 3 d$ emission decrease with increasing deposition.

In addition to the x-ray photoelectron spectra also UPS measurements (Fig. 14) have been performed to determine the work function as well as to verify the XPS results. The intensity of the Cd $4 d$ emission in Fig. 14 is also decreasing with deposition time. With increasing deposition time, the valence-band structure changes from a CdTe- to a Te-like shape. No shift of the $\mathrm{Cd} 4 d \mathrm{BE}$ is visible, in agreement with the XPS data. The distance of the valence-band maximum with respect to the Fermi level for CdTe of $E_{F}-E_{\mathrm{VBM}}$ $=0.68 \pm 0.05 \mathrm{eV}$ also agrees with the value determined from XPS core-level and valence-band spectra. The work function difference between the CdTe substrate and a thick Te layer (determined after $16 \mathrm{~min}$ of deposition) is relatively small $(0.3 \mathrm{eV})$.

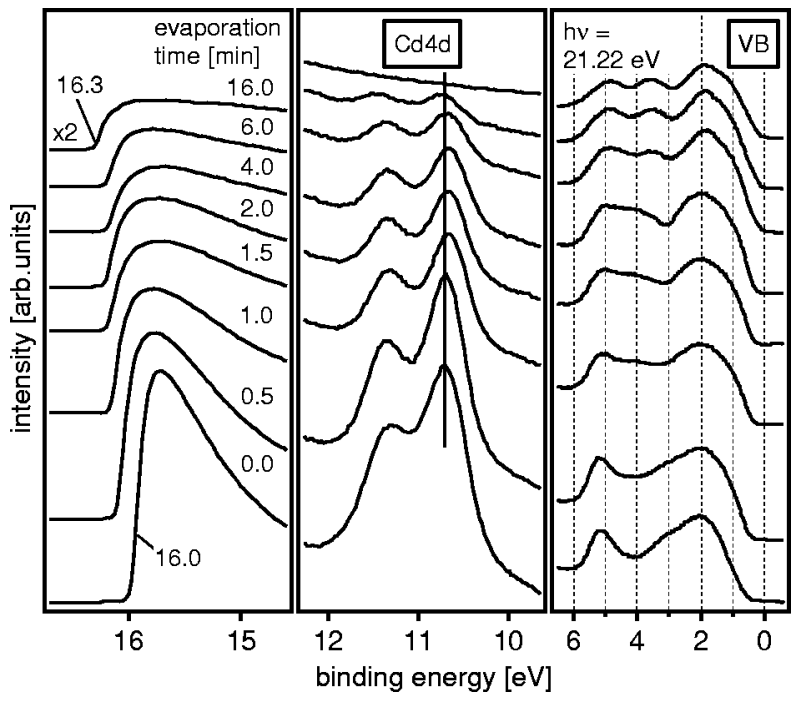

FIG. 14. Ultraviolet photoelectron spectra of the stepwise Te deposition. 


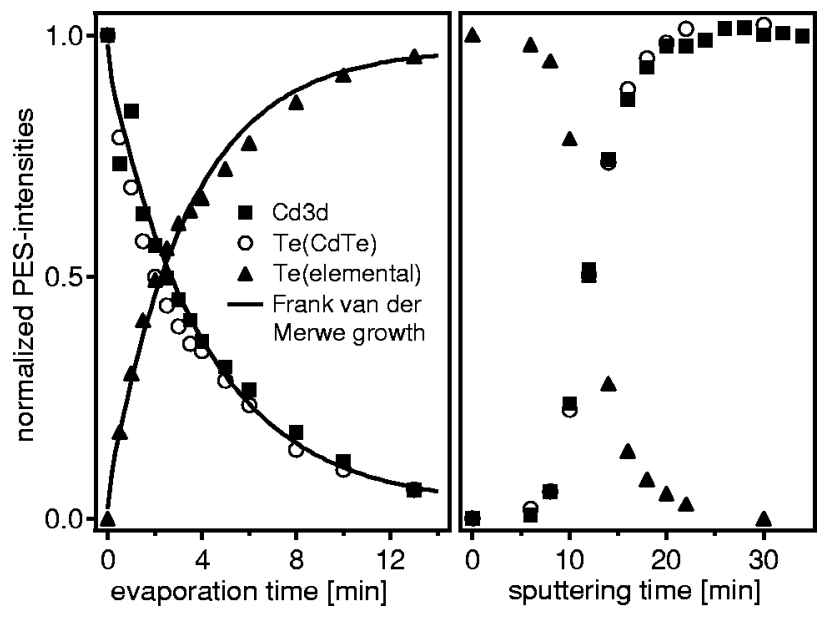

FIG. 15. Normalized photoelectron intensities of the Te $3 d_{5 / 2}$ and $\mathrm{Cd} 3 d_{5 / 2}$ core levels for a Te evaporated (left-hand side and after sputtering sample (right-hand side) (see Fig. 13).

The normalized photoelectron intensities of the Te $3 d_{5 / 2}$ and $\mathrm{Cd} 3 d_{5 / 2}$ core levels shown in Fig. 15 indicate a layerby-layer (Frank van der Merwe) growth. The intensities and BEs of the two different Te components are determined using the same curve fitting routine and peak composition as applied to the spectra of the etched samples. After deposition times extending $18 \mathrm{~min}$, the emission lines of the CdTe substrate are no longer detected implying a Te film thickness of more than $50 \AA$ (regarding the mean-free path of the electrons). The calculated lines in Fig. 15 correspond to the exponential equations $e^{-d / \lambda}$, and $1-e^{-d / \lambda}$. For longer evaporation times up to $63 \mathrm{~min}$, no further changes occur in the spectra. The clear correlation between the increasing intensity of the elemental Te $3 d_{5 / 2}$ core level and the decreasing intensity of the substrate emissions indicates that the $\mathrm{Te}$ deposition leads to a homogenous layer growth.

XPS depth profiling (Fig. 15) shows that evidently after a sputtering time of $25 \mathrm{~min}$, the Te layer is totally removed. The intensities of the $\mathrm{Te} 3 d_{5 / 2}(\mathrm{CdTe})$ and $\mathrm{Cd} 3 d_{5 / 2}$ levels show a parallel increase as a function of sputtering time, indicating that no preferential sputtering occurs. In comparison to the sputter depth profile shown in Fig. 8, for the etched sample, the transition region between CdTe and Te is considerably sharper.

In Fig. 16, the Te $3 d_{5 / 2}$ BEs are shown as a function of deposition time [Fig. 16(a)] and sputtering time [Fig. 16(b)]. An almost identical behavior is observed for evaporation and depth profiling. First, the BEs of the Te $3 d_{5 / 2}$ level and the $\mathrm{Cd} 3 d_{5 / 2}$ level (not shown) does not change significantly with the thickness of the Te layer for the evaporation and the depth profile experiment. We take this as evidence that sputtering does not induce defect levels, which affect the Fermilevel position. In contrast to the BEs of the CdTe substrate, the Te $3 d$ core level of the elemental Te overlayer shows a $200 \mathrm{meV}$ larger BE at low Te film thickness compared to the thick Te film. We attribute this effect to the formation of an amorphous layer at low coverage. A crystalline Te layer is only formed for a film thickness of $\geqslant 25 \AA$. The Fermi-level position in the CdTe substrate is given by $E_{F}-E_{\mathrm{VBM}}=0.65$ $\pm 0.05 \mathrm{eV}$. It is not changed with Te deposition. Because of

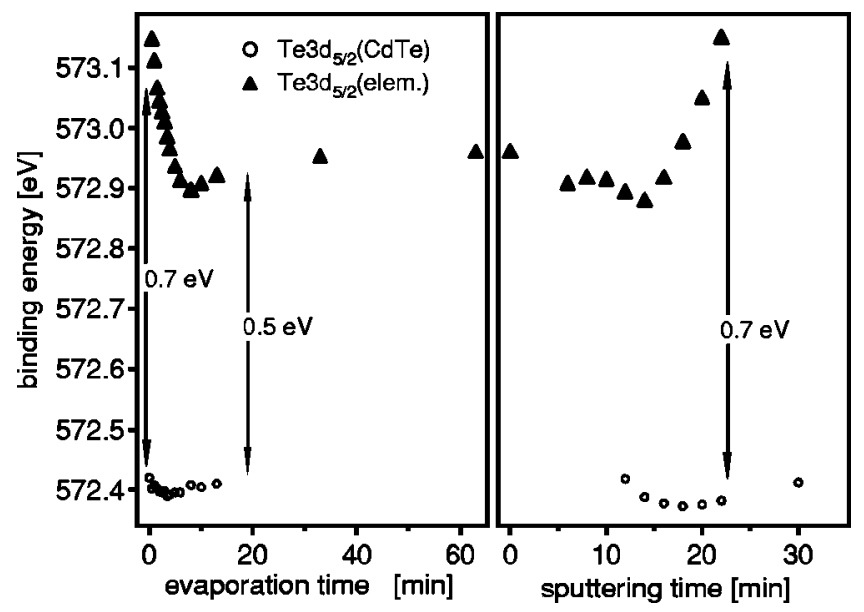

FIG. 16. Te $3 d_{5 / 2}$ BEs for (a) Te evaporated onto a sputter cleaned CdTe substrate and (b) subsequent sputter depth profiling. The BEs are determined from curve fitting of the spectra shown in Fig. 13.

the thickness dependence of the binding energies of the elemental Te layer, the determination of the valence-band offset requires a further assumption. As the electronic structure of the Te layer might not be fully developed at lower coverage, it seems reasonable to use the values determined at larger Te thicknesses, where an almost constant $\mathrm{BE}$ of the Te $3 d$ level is observed. The BE difference between the elemental and the CdTe component of the Te $3 d$ emission amounts to $0.5 \pm 0.05 \mathrm{eV}$ for Te evaporation times between 6-13 min. This is only slightly smaller than the energy difference of $0.55 \mathrm{eV}$, which has been observed at the etched samples. The band energy diagram for the $\mathrm{CdTe} / \mathrm{Te}$ interface prepared by vacuum evaporation of $\mathrm{Te}$ is, hence, essentially similar to those found for chemically CdTe surfaces (see Fig. 12) with a valence-band offset of $\Delta E_{\mathrm{VB}}=0.51 \mathrm{eV}$.

\section{Discussion}

We have presented the first characterization of the electronic interface properties between $\mathrm{CdTe}$ and $\mathrm{Te}$ as prepared by chemical etching of polycrystalline CdTe layers deposited by CSS. The interface between CdTe and Te is characterized by a valence-band offset of $\Delta E_{\mathrm{VB}} \sim 0.5 \mathrm{eV}$, where the Te valence-band maximum lies above that of CdTe. The barrier does not depend on the preparation of the interface. The independence of the barrier height on preparation condition agrees with electrical studies, which also show no significant differences between CdTe solar cells prepared with chemically etched or evaporated Te layers. ${ }^{43}$ Furthermore, we could not detect any influence of the native surface oxide of CdTe. The valence-band offsets determined in this study are significantly larger than the value of $\Delta E_{\mathrm{VB}}=0.26 \mathrm{eV}$ given by Niles et l. $^{42}$ for the interface between CdTe and evaporated Te layers. The origin of the difference is unclear to us. Niles et $a l .{ }^{42}$ used a different procedure to determine the valence-band offset, i.e., they directly used the difference of the valence-band maxima of CdTe and Te in UPS. This procedure is justified, as there is no band bending in the CdTe substrate induced by Te deposition. With this procedure, we determine a band offset of $\Delta E_{\mathrm{VB}}=0.4 \pm 0.01 \mathrm{eV}$ from the 
UPS data presented in Fig. 14, which agrees with our value determined from XPS and is also larger than the value given by Niles et al. ${ }^{42}$ Another difference between our work and theirs is the lower surface sensitivity in our XPS measurements, which results from the use of $\mathrm{Al} K \alpha$ radiation, instead of low-energy synchrotron radiation. This allows us to follow the BEs of the CdTe substrates up to a higher Te film thickness.

There is another difference between the data presented here and the results of Niles et al., ${ }^{42}$ which concerns the Fermi-level position in the Te layer. Our spectra indicate a Fermi-level position in the Te layer of $E_{F}-E_{\mathrm{VBM}}=0.17$ $\pm 0.05 \mathrm{eV}$. Niles et al. $^{42}$ reported a Fermi-level position in the Te layer of $E_{F}-E_{\mathrm{VBM}} \approx 0.37 \mathrm{eV}$ for a Te film thickness of $26 \AA$, which changes to $E_{F}-E_{\mathrm{VBM}} \approx 0.02 \mathrm{eV}$ for a thickness of $76 \AA$. We do not observe a highly $p$-doped Te layer at larger coverage, independent of the preparation of the Te layer.

Good contact properties of the $\mathrm{CdTe} / \mathrm{Te}$ interface have been concluded by Niles et al. ${ }^{42,43}$ This has been attributed to: (i) the small valence-band offset at the interface, and (ii) the strong $p$-type doping of thicker Te layers. Together, these results lead to a Fermi-level position $\sim 0.3 \mathrm{eV}$ above the valence-band maximum of CdTe at the interface. Such a low barrier height would not hinder current flow. In contrast, we have found a significantly larger barrier height of almost 0.7 $\mathrm{eV}$ for both chemically etched and evaporated $\mathrm{CdTe} / \mathrm{Te}$ interfaces (see Fig. 12). The larger barrier results from a larger valence-band offset and a higher Fermi-level position.

In an electrical analysis of CdTe solar cells with a chemically etched Te layer, a barrier of $0.5 \mathrm{eV}$ has been assumed at the back contact. ${ }^{19}$ This agrees with our experimental value for the valence-band offset at the $\mathrm{CdTe} / \mathrm{Te}$ interface, indicating a modification of the Fermi-level position by subsequent processing steps (metallization). The Fermi level will be easily modified within the band gap of the Te layer. A back contact barrier of $0.5 \mathrm{eV}$ is achieved with a highly $p$-doped Te $\left(E_{F}-E_{\mathrm{VBM}} \sim 0 \mathrm{eV}\right)$, which, based on our results, can be considered as the lower limit for the Fermilevel position and, hence, the contact barrier.

In the band energy diagram presented in Fig. 12, we have assumed a Fermi-level position in the CdTe bulk of $E_{F}-E_{\mathrm{VBM}}=0.29 \mathrm{eV}$. Recall that we do not observe high p-type CdTe doping, which is essential for forming a thin barrier. Our data rather indicate an intrinsic CdTe with $E_{F}$ $-E_{\mathrm{VBM}}=0.65-0.7 \mathrm{eV}$ for sputter cleaned CdTe surfaces. Doping of the CdTe in the solar cell is thus rather achieved by the diffusion of dopants from the subsequent layers, which are deposited onto the etched surface.

\section{SUMMARY AND CONCLUSIONS: ROLE OF TE FOR BACK CONTACT FORMATION}

The morphologic and electronic properties of $\mathrm{Te}$ as an intermediate layer in the back contact for CdTe thin film solar cells has been studied with XPS, UPS, GIXRD, SEM, AFM, and SIMS. The Te film has been formed by wetchemical etching of a polycrystalline CdTe surface with NP etch. This process eliminates the surface oxide and dissolves the $\mathrm{Cd}$ gradually from the $\mathrm{CdTe}$. Etching leads to a polycrys- talline elemental Te layer of about $80 \AA$ thickness on top of a CdTe transition region with an accumulation of elemental Te along the grain boundaries. The etched surfaces show a $\mathrm{Cd}$ concentration of about $10 \%$, which are explained either by CdTe inclusions in a porous Te layer, or by selective etching of particular surface orientations. Both explanations are in agreement with the observed microroughening of the etched surface compared to the original CdTe morphology. Selective etching might be important, as different surface orientations can lead to different contact properties. Nevertheless, the orientation dependence of CdTe etching needs to be investigated.

The $\mathrm{CdTe} / \mathrm{Te}$ interface is characterized by a valenceband offset of $\Delta E_{\mathrm{VB}}=0.5 \pm 0.1 \mathrm{eV}$. This result is independent of the preparation of the interface and determines the lower limit for the back contact barrier for contacts including a Te layer. The barrier agrees with electrical simulations. However, a highly $p$-doped Te layer has to be assumed for a $0.5 \mathrm{eV}$ barrier, which is not observed in our experiments. We find rather an intrinsic Te layer, resulting in a barrier of $\sim 0.7 \mathrm{eV}$. Thus subsequent processing of the back contact is evidently required to achieve a $p$-type Te or metal telluride layer and a reasonably low barrier. These processing steps may be related to the subsequent deposition of metals onto the Te interface layer. The experimentally observed variation in the quality of the contacts must be related rather to the thickness and reactivity of the preformed Te layer forming tellurides than to the properties of Te itself.

\section{ACKNOWLEDGMENTS}

The authors would like to thank ANTEC Technology $\mathrm{GmbH}$ for the intensive discussions, insights into the production process of CdTe solar cells, and delivery of CdTe samples. They also would like to thank Patrick Hoffmann, Ricardo Mikalo, David Batchelor, and Dieter Schmeisser from the BTU Cottbus for their support during our beamtime at the undulator/monochromator U49/2 PGM2 at BESSY II in Berlin, and Martin Beerbom for his assistance in using the electrochemistry chamber. Of course, the colleagues of their group have to be acknowledged for their cooperative interactions. This work was supported by the Bundesministerium für Wirtschaft (BmWi), Grant No. 0329857.

\footnotetext{
${ }^{1}$ T. L. Chu, S. S. Chu, C. Ferekides, C. Q. Wu, J. Britt, and C. Wang, J. Appl. Phys. 70, 7608 (1991).

${ }^{2}$ J. Britt and C. Ferekides, Appl. Phys. Lett. 62, 2851 (1993).

${ }^{3}$ X. Wu, J. C. Keane, C. DeHart, R. G. Dhere, D. S. Albin, A. Duda, T. A. Gessert, D. H. Levi, and P. Sheldon, Proceedings of the 17th European Photovoltaic Solar Energy Conference, München (WIP Munic and ETA Florence, 2001), p. 995.

${ }^{4}$ X. Wu, S. Asher, D. H. Levi, D. E. King, Y. Yan, T. A. Gessert, and P. Sheldon, J. Appl. Phys. 89, 4564 (2001).

${ }^{5}$ D. Bonnet, Thin Solid Films 361, 547 (2000).

${ }^{6}$ R. H. Bube, Photovoltaic Materials (Imperial College Press, London, 1998).

${ }^{7}$ T. L. Chu, Cadmium Telluride Solar Cells, in Current Topics in Photovoltaics (Academic, New York, 1988).

${ }^{8}$ G. Gordillo, J. M. Florez, and L. C. Hernandez, Sol. Energy Mater. Sol. Cells 37, 273 (1995).

${ }^{9}$ D. H. Rose, F. S. Hasoon, R. G. Dhere, D. S. Albin, R. M. Ribelin, X. S. Li, Y. Mahathongdy, T. A. Gessert, and P. Sheldon, Prog. Photovoltaics 7, 331 (1999).
} 
${ }^{10}$ B. E. McCandless, L. W. Moulton, and R. W. Birkmire, Prog. Photovoltaics 5, 249 (1997).

${ }^{11}$ B. E. McCandless, I. Youm, and R. W. Birkmire, Prog. Photovoltaics 7, 21 (1999).

${ }^{12}$ J. Fritsche, S. Gunst, A. Thissen, R. Gegenwart, A. Klein, and W. Jaegermann, Mater. Res. Soc. Symp. Proc. 668, H5.1 (2001).

${ }^{13}$ J. Fritsche, D. Kraft, A. Thissen, T. Mayer, A. Klein, and W. Jaegermann, Mater. Res. Soc. Symp. Proc. 668, H6.6 (2001).

${ }^{14}$ J. Fritsche, D. Kraft, A. Thissen, T. Mayer, A. Klein, and W. Jaegermann, Thin Solid Films 403, 252 (2002).

${ }^{15}$ J. Fritsche, A. Thissen, A. Klein, and W. Jaegermann, Thin Solid Films 387, 158 (2001).

${ }^{16}$ J. Fritsche, T. Schulmeyer, D. Kraft, A. Thissen, A. Klein, and W. Jaegermann, Appl. Phys. Lett. 81, 2297 (2002).

${ }^{17}$ D. Kraft, A. Thissen, M. Campo, M. Beerbom, T. Mayer, A. Klein, and W. Jaegermann, Mater. Res. Soc. Symp. Proc. 668, H7 (2001).

${ }^{18}$ D. W. Niles, D. Rioux, and H. Höchst, J. Appl. Phys. 73, 4586 (1993).

${ }^{19}$ M. Köntges, R. Reineke-Koch, P. Nollet, J. Beier, R. Schäffler, and J. Parisi, Thin Solid Films 403, 280 (2002).

${ }^{20}$ A. Niemegeers and M. Burgelman, J. Appl. Phys. 81, 2881 (1997).

${ }^{21}$ T. J. McMahon and A. L. Fahrenbruch, Proceedings of the 28th IEEE Photovoltaic Specialists Conference (IEEE, Piscataway, NJ, 2000), p. 539.

${ }^{22}$ K. D. Dobson, I. Visoly-Fisher, G. Hodes, and D. Cahen, Sol. Energy Mater. Sol. Cells 62, 295 (2000).

${ }^{23}$ D. L. Bätzner, R. Wendt, A. Romeo, H. Zogg, and A. N. Tiwari, Thin Solid Films 361, 463 (2000).

${ }^{24}$ D. L. Bätzner, A. Romeo, H. Zogg, R. Wendt, and A. N. Tiwari, Thin Solid Films 387, 151 (2001).

${ }^{25}$ W. Mönch, Semiconductor Surfaces and Interfaces (Springer, Heidelberg, 1993).

${ }^{26}$ E. H. Rhoderick and R. H. Williams, Metal-Semiconductor Contacts (Clarendon, Oxford, 1988).

${ }^{27}$ V. L. Rideout, Solid-State Electron. 18, 541 (1975).

${ }^{28}$ D. Rioux, D. W. Niles, and H. Höchst, J. Appl. Phys. 73, 8381 (1993).

${ }^{29}$ T. Gessert, J. Vac. Sci. Technol. A 14, 806 (1996).

${ }^{30}$ J. Drayton, A. Gupta, K. Makhratchev, K. J. Price, R. G. Bohn, and A. D. Compaan, Mater. Res. Soc. Symp. Proc. 668, H5.9 (2001).

${ }^{31}$ A. Romeo, D. L. Bätzner, H. Zogg, and A. N. Tiwari, Proceedings of the 16th European Photovoltaic Solar Energy Conference, Glasgow, 843 (H. S. Stephens, Bedford, 2000).

${ }^{32}$ N. Romeo, A. Bosio, R. Tedeschi, and V. Canevari, Thin Solid Films 361, $327(2000)$

${ }^{33}$ T. Schmidt, K. Durose, C. Rothenhausler, and M. Lerch, Thin Solid Films 361, 383 (2000).
${ }^{34}$ A. E. Abken and O. J. Bartelt, Thin Solid Films 403, 216 (2002).

${ }^{35}$ G. Leimkühler, O. Bartelt, and R. Reineke-Koch, Proceedings of the 17th European Photovoltaic Solar Energy Conference, Munich, Germany (WIP Munic and ETA Florence, 2001), p. 1169.

${ }^{36}$ H. Uda, S. Ikegami, and H. Sonomura, Jpn. J. Appl. Phys., Part 1 36, 5549 (1997).

${ }^{37}$ H. Uda, S. Ikegami, and H. Sonomura, Sol. Energy Mater. Sol. Cells 50, 141 (1998).

${ }^{38}$ C. S. Ferekides, V. Viswanathan, and D. L. Morel, Proceedings of the 26th IEEE Photovoltaic Specialists Conference, Anaheim, CA (IEEE, New York, 423 (1997), p. 423.

${ }^{39}$ J. H. Yun, K. H. Kim, D. Y. Lee, and B. T. Ahn, Sol. Energy Mater. Sol. Cells 75, 203 (2003).

${ }^{40}$ D. Grecu, A. D. Compaan, D. Young, U. Jayamaha, and D. H. Rose, J. Appl. Phys. 88, 2490 (2000).

${ }^{41}$ J. Sarlund, M. Ritala, M. Leskelä, E. Siponmaa, and R. Zilliacus, Sol. Energy Mater. Sol. Cells 44, 177 (1996).

${ }^{42}$ D. W. Niles, X. Li, P. Sheldon, and H. Höchst, J. Appl. Phys. 77, 4489 (1995).

${ }^{43}$ D. W. Niles, L. Xiaonau, D. Albin, D. Rose, T. Gessert, and P. Sheldon, Prog. Photovoltaics 4, 225 (1996).

${ }^{44}$ M. Beerbom, O. Henrion, A. Klein, T. Mayer, and W. Jaegermann, Electrochim. Acta 45, 4663 (2000).

${ }^{45}$ D. Bonnet and M. Harr, Proceedings of the Second International Conference on Photovoltaic Solar Energy Conv., Vienna, 397 (1998).

${ }^{46}$ K.-F. Chien, A. L. Fahrenbruch, and R. H. Bube, J. Appl. Phys. 64, 2792 (1988).

${ }^{47}$ J. Fritsche, S. Gunst, E. Golusda, M. C. Lejard, A. Thissen, T. Mayer, A. Klein, R. Wendt, R. Gegenwart, D. Bonnet, and W. Jaegermann, Thin Solid Films 387, 161 (2001).

${ }^{48}$ D. Kraft, A. Thissen, A. Klein, and W. Jaegermann (unpublished).

${ }^{49}$ X. Li, D. W. Niles, F. Hasoon, R. Matson, and P. Sheldon, J. Vac. Sci. Technol. A 17, 805 (1999).

${ }^{50}$ T. J. Yang and T. B. Wu, Jpn. J. Appl. Phys., Part 1 34, 6184 (1995).

${ }^{51} \mathrm{~J}$. McHardy and F. Ludwig, Electrochemistry of Semiconductors and Electronics (Noyes, Park Ridge, NJ, 1992).

${ }^{52}$ J. R. Waldrop, R. W. Grant, S. P. Kowalczyk, and E. A. Kraut, J. Vac. Sci. Technol. A 3, 835 (1985).

${ }^{53}$ O. Madelung, Semiconductors Basic Data (Springer, Berlin, 1996).

${ }^{54}$ M. Burgelman, S. Degrave, and P. Nollet, Appl. Phys. A: Mater. Sci. Process. 63, 149 (1999).

This article may be downloaded for personal use only. Any other use requires prior permission of the author and AIP Publishing. This article appeared in Journal of Applied Physics 94, 3589 (2003) and may be found at https://doi.org/10.1063/1.1597757.

Available under only the rights of use according to UrhG. 